\title{
Why read academic journals any more?
}

\author{
Peter Klaus
}

Published online: 31 January 2013

(c) Springer-Verlag Berlin Heidelberg 2013

Just a few weeks ago I overheard an academic colleague suggest in a discussion that "the habit of reading academic journals really no longer is in sync with our times": Google and other electronic searching devices now offer the capability for every researcher and author to do "on demand", perfectly project-specific inquiries into the fast growing electronic repositories of published materials. This is both more time-efficient, she argued, and yields-with some likelihood-results on research questions at hand that are broader and richer than what even perseverant traditional readers of academic journals can hope to extract and retain from their "anticipatory" general scanning and studying of their peers' work.

Right? The idea of giving up general reading of academic journals at first sight sounds like a radical departure from the traditional values and habits of academia. But then, upon second consideration, don't we logisticians consider the shift from "push" to "pull" activation of industrial supply chains as the more modern, more effective practice in many instances? Why should this not apply to knowledge supply chains as well?

And being honest to ourselves: Is not the rate of articles which most of us actually read and study out of general interest in our field's academic journals very, very low?

Or wrong? Don't we loose an important source of inspiration and access to new knowledge if we completely abandone the traditional academic habit of general, "serenditpitous" reading-i.e. reading which is not focused on a single, preconsidered question, but provides multiple chances to make unexpected, "pleasant discoveries"?

P. Klaus $(\square)$

Nuremberg, Germany

e-mail: peter.klaus@wiso.uni-erlangen.de

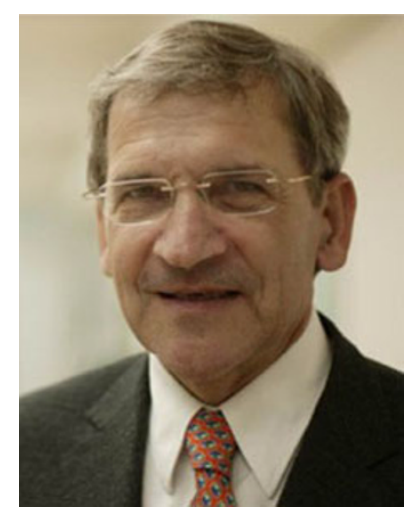

I do not want to be unrealistic. It is an element of today's academic reality that the value of publishing and publications is more often with the authors than with readers. The process of researching, writing, and revising papers increases authors' insight in their chosen field of research. Adding references on their lists of publications helps their careers! Assisting authors to serve these purposes is an important and legitimate function of academic journals.

But I like to make the argument that a balance between project-specific "on demand" reading behavior, however time-efficient, and a habit of some broader, less directed scanning and studying of one's academic peers' work is indispensible for the advancement of scientific knowlegde. In modest ways, I think, this can be proven by looking at the-quite incidental-selection of articles which our reviewers suggested for this issue of LOGISTICS RESEARCH:

The papers by Sharma/Lote and Van Le/Huyngh/Claudiu/Achim relate to the much discussed phenomenon oft he "Bullwhip Effect" in supply chains. Sharma/Lote suggest to apply the analogy of vibrations and mechanisms of dampening vibrations to an interesting case of demand volatility. They may inspire "Bullwhip Effect" researchers to come up with new kinds of policies to successfully reduce system vibrations. A similar promise may be in Van Le/Huyngh/Claudiu/Achim's research on the effects of inventory sharing on the Bullwhip Effect.

The paper by Drezner, if read not from the technical perspective of a Quantitiative Methods expert, but-more broadly-as a contribution to the advancement of knowledge shows similarity in a set of location problems which otherwise were seen as not related. Weichert/et al.'s paper on technologies for automating the task of unstacking pallets offers a "new combination" of such technologies. 
Last not least, the paper by Sebastian/Bui/Hempsch shows how negotiation processes, which are taking place between actors in supply chains, could be automated through the application of multi-agent technology. It is an impressive example of how the distant worlds of research on people's behaviors and sophisticated information technology applications could be brought together for innovative problem solutions.

I repeat the point that I was trying to make with thesemaybe quite inadequate-interpretations of typical journal papers in our field: Even if we are not able to fully appreciate and evaluate the technicalities of many subjects published in a heterogenous field like Logistics, we will discover new questions and get inspiration from further than what a focused Internet search offers. That, in itself, makes scanning and reading academic journals worthwhile. Best regards,

Yours

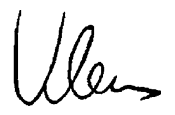

Peter Klaus

Editor-in-Chief LOGISTIS RESEARCH

December 2012 